\title{
Influence of lactation on motor activity and elevated plus maze behavior
}

\author{
M.R.P. Silva ${ }^{1}$, \\ M.M. Bernardi ${ }^{1}$, \\ A.G. Nasello ${ }^{2}$ and \\ L.F. Felicio ${ }^{1}$
}

\author{
${ }^{1}$ Departamento de Patologia, Faculdade de Medicina Veterinária e Zootecnia, \\ Universidade de São Paulo, 05340-900 São Paulo, SP, Brasil \\ ${ }^{2}$ Departamento de Ciências Fisiológicas, Faculdade de Medicina da Santa Casa de \\ São Paulo, 01277-900 São Paulo, SP, Brasil
}

\author{
Correspondence \\ L.F. Felicio \\ Departamento de Patologia \\ Faculdade de Medicina Veterinária \\ e Zootecnia, USP \\ Av. Prof. Orlando M. de Paiva, 87 \\ 05508-900 São Paulo, SP \\ Brasil \\ Fax: 55 (011) 818-7829 \\ E-mail: Ifelicio@usp.br \\ Presented at the XI Annual Meeting \\ of the Federação de Sociedades de \\ Biologia Experimental, Caxambu, \\ MG, Brasil, August 21-24, 1996. \\ Research supported by FAPESP \\ (No. 92/1245-9) and CNPq \\ (No. 500307/92).
}

\begin{abstract}
Lactating rats show less noise-induced freezing and fewer inhibitory responses on the 6th day post-delivery when submitted to water and food deprivation in a classical conflict paradigm. Lactating mice go more often to the illuminated chamber in a light-dark cage and stay longer in it than virgin females. The present study was designed to assess the influence of this physiological state, i.e. lactation, on the elevated plus maze (EPM) and open-field behavior in adult female rats. Total (TL) and central (CL) locomotion and rearing (RF) frequencies were measured in an open-field. Number of entries into the open and closed arms as well as the time spent in each of these arms were measured in the EPM. Percent time spent and number of entries into the open arms were calculated and compared. In the open-field, TL was significantly decreased $(115 \pm 10.6$ vs $150 \pm 11.6)$ while CL and RF did not differ from those presented by virgin rats. In the EPM, lactating rats displayed a significant reduction in percent time spent $(10.9 \pm 1.5 v s 17.4 \pm 2.3)$ in the open arms as well as a tendency to a reduction in percent entries into the open arms $(35.7 \pm 4.7$ vs $45.7 \pm$ 4.3). These results show that the physiological state of lactation modulates the open-field and EPM behaviors in rats.
\end{abstract}

Key words

- Female rats

- Anxiety

- Elevated plus maze

- Open-field test

- Lactation
Changes in the physiological states of mammals are usually related to endocrine and neural changes (1-3) and implicate behavioral adjustments or alterations (4). After giving birth and during lactation the female rat undergoes peripheral and central physiological changes. These changes ultimately reflect the biologically useful appearance of some behaviors and modulation of others such as taking care of the pups and aggression, respectively $(4,5)$. Motherhood in rodents induces a reduced reactivity to normally aversive stimuli (6-8). Lactating rats are less inclined to run away from an intruder
(6) and have lower reactivity in classical conflict tests (8). In a light/dark choice situation, lactating mice displayed less avoidance of the aversive illuminated environment than did virgin animals (5). Since these measurements are affected by anxiolytic compounds $(9,10)$, the interpretation that usually arises from these investigations is that lactating rodents are in a physiologically induced low-anxiety state. However, the fact that maternal rodents are hyperphagic (11) may make them more hungry and hence more able to press a bar to receive food or water even knowing they are going to receive a 
shock, implying that the motivational state cannot be ruled out in this scenario. In addition, the higher defecation score of lactating females is usually interpreted as suggestive that these animals have higher emotionality levels than virgin females. The present study was designed to assess the influence of this physiological state, i.e. lactation, on the general activity measured in an open-field and in the more recently designed anxiolytic drugsensitive paradigm, the elevated plus maze (EPM) test, in adult female rats. The objective of this investigation was to compare the performance on the EPM and open-field arena with earlier experiments using punished drinking (e.g. conflict tests) and feeding in a novel arena.

Nine female rats (Wistar origin, 200-250 g) on the 6th postpartum lactating day and 10 age-matched virgin females were used. The animals were kept on a controlled 12-h lightdark cycle (lights on at 6:00 h) with food and water available ad libitum throughout the experiment. The animals used in this study were maintained in accordance with the guidelines of the Committee on Care and Use of Laboratory Animal Resources, National Research Council, USA. All rats were tested for general activity in an open-field and in an elevated plus maze apparatus. The open-field arena was as described previously (12). Briefly, the open-field used was $80 \mathrm{~cm}$ in diameter and $30 \mathrm{~cm}$ in height. The openfield was washed with a water-alcohol (5\%)

Table 1 - Open-field test behavior of age-matched female virgin $(N=10)$ and 6th day postpartum lactating $(\mathrm{N}=9)$ rats.

Data are reported as means \pm SEM. ${ }^{*} \mathrm{P}<0.05$ compared to virgin rats (two-tailed Student $t$-test).

\begin{tabular}{lcc}
\hline Parameters & Virgin rats & Lactating rats \\
\hline $\begin{array}{l}\text { Total locomotion } \\
\text { activity }\end{array}$ & $150 \pm 11.6$ & $115 \pm 10.6^{*}$ \\
$\begin{array}{l}\text { Central locomotion } \\
\text { activity }\end{array}$ & $26 \pm 3.6$ & $26 \pm 7.1$ \\
Total rearing & $25 \pm 4.5$ & $21 \pm 3.3$
\end{tabular}

solution before behavioral testing to eliminate possible bias due to odors left by previous subjects. To minimize possible circadian influences on rat open-field behavior, experimental and control observations were alternated. A hand-operated counter was employed to score total (TL; number of floor units entered) and central (CL; number of central floor units crossed) locomotion, and rearing (RF) frequencies for $5 \mathrm{~min}$. The elevated plus maze test was as previously described $(13,14)$. Briefly, the plus maze was made of wood with two open arms (50 x 10 $\mathrm{cm}$ ) and opposite closed arms of the same size but with $40-\mathrm{cm}$ high walls. The arms were connected by a central square and thus formed a plus sign. The apparatus was elevated $50 \mathrm{~cm}$ above the floor. Each rat was placed in the central square of the plus maze facing an enclosed arm. The time spent in enclosed and open arms was scored for 5 min. An arm entry was defined as an animal entering the arm with all four feet and the number of entries into open and enclosed arms was scored (14). The results were compared by the two-tailed Student $t$-test. The probability of $\mathrm{P}<0.05$ was taken to be a significant difference for all comparisons made.

In the open-field, TL displayed by lactating animals was significantly decreased (115 \pm 10.6 vs $150 \pm 11.6 ; \mathrm{P}=0.03$ ) while $\mathrm{CL}$ and RF were not different from those shown by virgin rats (Table 1). Table 2 shows the results obtained in the plus maze test. Lactating rats displayed reduction in percent time spent $(10.9 \pm 1.5$ vs $17.4 \pm 2.3 ; \mathrm{P}=0.04)$ in the open arms and tended to show reduction in percent entries into the open arms (35.7 \pm 4.7 vs $45.7 \pm 4.3 ; \mathrm{P}=0.07$ ).

Endocrine, neural and behavioral changes observed during lactation have been extensively described $(1-4,15,16)$. In humans, the early postpartum period is a time of increased emotional lability. Postpartum psychological disorders are complex and include genetic and physiological factors. Increased 
levels of anxiety are among the milder forms of emotional alterations that occur during the early postpartum period (17). The present study shows that the state of lactation modulates the open-field and EPM behaviors in rats. The data show a reduction in ambulation and in time spent in the open arms in lactating rats. Although the openfield data may be interpreted as being suggestive of changes in motor activity, the results failed to show any lactation-induced change in the total arm entries, or the number of entries into the closed arms, which are indices of motor activity in the EPM. Thus, the decrease in locomotion frequency observed in lactating rats may be due to a novelty-induced increase in emotionality. Lactating rodents submitted to anxiolytic drug-sensitive behavioral tests usually show responses that are interpreted to suggest a low anxiety state. However, these data are not consistent since defecation, a parameter that indicates an increase in emotionality, is increased during this period (5). In addition, since female rats eat and drink more during lactation, the conflict test paradigms would be biased by the increased appetite of the postparturient rat. An increase or decrease in central locomotion activity in the open-field suggests a higher or lower anxiety state, respectively. Virgin and lactating rats presented virtually the same central locomotion activity, a fact suggesting that this parameter is not sensitive enough to detect differences in anxiety during lactation. The EPM test was used in this study to assess anxiety levels since this approach is less aversive and more sensitive to anxiolytic drugs, making the EPM a potentially informative behavioral test to measure anxiety during the postpartum period. The reduction in percent

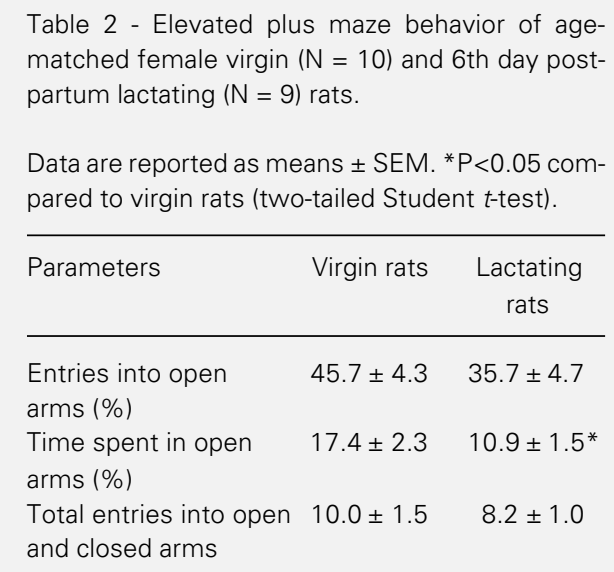

Table 2 - Elevated plus maze behavior of agematched female virgin $(N=10)$ and 6th day postpartum lactating $(\mathrm{N}=9)$ rats.

Data are reported as means \pm SEM. ${ }^{*} \mathrm{P}<0.05 \mathrm{com}-$ pared to virgin rats (two-tailed Student $t$-test).

\begin{tabular}{lcc}
\hline Parameters & Virgin rats & $\begin{array}{c}\text { Lactating } \\
\text { rats }\end{array}$ \\
\hline $\begin{array}{l}\text { Entries into open } \\
\text { arms (\%) }\end{array}$ & $45.7 \pm 4.3$ & $35.7 \pm 4.7$ \\
$\begin{array}{l}\text { Time spent in open } \\
\text { arms (\%) }\end{array}$ & $17.4 \pm 2.3$ & $10.9 \pm 1.5^{*}$ \\
$\begin{array}{l}\text { Total entries into open } \\
\text { and closed arms }\end{array}$ & $10.0 \pm 1.5$ & $8.2 \pm 1.0$ \\
\end{tabular}

time spent in the open-arms as well as the tendency to reduce the percent of entries into these arms displayed by lactating rats in the EPM may be due to an anxiogenic-like effect of lactation. This increase in anxiety may lead to a freezing that ultimately leads to a reduction in open-field total locomotion activity. The discrepancies between our results that suggest a postpartum-induced anxiety increase, and the results obtained by other investigators, implying an anxiolytic effect of lactation, may be due to the different methods employed to assess anxiety levels in this situation. Indeed, conflict tests and EPM are not equally sensitive to classical (e.g., benzodiazepines) and new (e.g., buspirone) anxiolytic drugs (18), with the EPM test being less aversive and more sensitive to anxiolytic factors. The data reported so far suggest that the classical tests are not the most adequate to assess anxiety levels during lactation. Alternatively, the complexity of this physiological state and its unique meaning for species survival may induce a particular kind of behavioral strategy based on a specific kind of anxiety. 


\section{References}

1. Bridges RS, Felicio LF, Pellerin LJ, Stuer AM \& Mann PE (1993). Prior parity reduces post-coital diurnal and nocturnal prolactin surges in rats. Life Sciences, 53: 439-445.

2. Felicio LF, Florio JC, Sider LH, CruzCasallas PE \& Bridges RS (1996). Reproductive experience increases striatal and hypothalamic dopamine levels in pregnant rats. Brain Research Bulletin, 40: 253-256.

3. Nasello AG, Tieppo CA \& Felicio LF (1995). Apomorphine-induced yawning in rat: influence of fasting and day time. Physiology and Behavior, 57: 967-971.

4. Numan M (1994). Maternal behavior. In: Knobil E \& Neill JD (Editors), The Physiology of Reproduction. 2nd edn. Raven Press, New York, 221-302.

5. Maestripieri D \& D'Amato FR (1991). Anxiety and maternal aggression in house mice (Mus musculus): a look at interindividual variability. Journal of Comparative Psychology, 105: 295-301.

6. Fleming AS \& Luebke C (1981). Timidity prevents the virgin female from being a good mother: Emotionality differences between nulliparous and parturient females. Physiology and Behavior, 27: 863-868.

7. Hård E \& Hansen S (1985). Reduced fearfulness in the lactating rat. Physiology and Behavior, 35: 641-643.
8. Ferreira A, Hansen $S$, Nielsen M, Archer T \& Minor BG (1989). Behavior of mother rats in conflict tests sensitive to antianxiety agents. Behavioral Neuroscience, 103: 193-201.

9. Costall B, Jones BJ, Kelly ME, Naylor RJ \& Tomkins DM (1989). Exploration of mice in a black and white test box: validation as a model of anxiety. Pharmacology, Biochemistry and Behavior, 32: 777-785.

10. Crawley JN (1981). Neuropharmacologic specificity of a simple animal model for the behavioral actions of benzodiazepines. Pharmacology, Biochemistry and Behavior, 15: 695-699.

11. Hansen S, Ferreira A \& Selart ME (1985). Behavioural similarities between mother rats and benzodiazepine-treated non maternal animals. Psychopharmacology, 86: 344-347.

12. Felicio LF, Nasello AG \& Palermo-Neto J (1987). Dopaminergic supersensitivity after long-term bromopride treatment. Physiology and Behavior, 41: 433-437.

13. Silva MRP, Felicio LF, Nasello AG \& Bernardi MM (1995). Is perinatal picrotoxin anxiogenic? Brazilian Journal of Medical and Biological Research, 28: 663666.
14. Pelow S, Chopin P, File SE \& Briley M (1985). Validation of open-closed arm entries in an elevated plus maze as measure of anxiety in the rat. Journal of Neuroscience Methods, 14: 149-167.

15. Felicio LF, Mann PE \& Bridges RS (1991) Intracerebroventricular cholecystokinin infusions block beta-endorphin-induced disruption of maternal behavior. Pharmacology, Biochemistry and Behavior, 39: 201204.

16. Mann PE, Felicio LF \& Bridges RS (1995) Investigation into the role of cholecystokinin (CCK) in the induction and maintenance of maternal behavior in rats. Hormones and Behavior, 29: 392-406.

17. Fava GA, Fava M, Kellner R, Serafini E \& Mastrogiacomo I (1981). Anxiety in hyperprolactinemic amenorrhea. Psychotherapy and Psychosomatics, 36: 122128.

18. Coplany JD, Wolk SI \& Klein DF (1995). Anxiety and the serotonin 1 A receptor. In: Bloom FE \& Kupfer DJ (Editors), Psychopharmacology: The Fourth Generation of Progress. Raven Press, New York, 13011310. 